\title{
THE GENUS ALSOPHIS IN THE PUERTO RICO AREA
}

Chapman Grant, Major, United States Army.

The genus Alsophis splits into two distinct species in the Puerto Rico region. The first has seventeen scale rows, at mid-body, and is known only from Pluerto Rico, Caja de Muertos, Desecheo and Mona Islands. The second, with nineteen rows, is known only from the Virgin Islands, Culebra and Pinero Islands. Pinero is less than a half mile from Medio Mundo Island, which in turn is separated only by a narrower channel from Puerto Rico. One would expect to find A. portoricensis instead of $A$ antillensis so close to the mainland and so for from Culebra or Vieques. This is another anomaly of distribution.

Stejneger and Schmidt lay emphasis on pattern in distinguishing the species of this genus. Schmidt split the Mona from the Puerto Rican form principally because of pattern. One can pick an almost typical form 'of any of these patterns from my series from any island; that is, the patterns overlap-are not wholly specific. Nevertheless, the patterns shown by Stejneger and Schmidt hold in the majority of eases from Mona, but specimens from Caja de Muertos average between the Mona, the Puerto Rico and the Culebra patterns.

Specimens from Culebra are reticulated above with clear white bellies; one with a continuous stripe on third, fourth, and fifth rows and with black bordered belly scales. These overlap the pattern of A. portoricensis. Aln A. portoricensis shows hardly any black on the belly, but with elaborate striping and variegated markings, thus at once bridging all three species. Caja de Muertos specimens show nearly perfect patterns of the three species. The Pinero specimens seemed at first to be slightly aberrant $A$. portoricensis, but they were A. antillensis.

Nevertheless, my quart bottles full of specimens can be sorted correctly using Stejneger \& Schmidt's text figures for a guide, except for the Caja de Muertos specimens, which are about equally divided between the three patterns. It seems wise to indorse the division as it now stands, but $A$. variegatus is very close indeed to $A$. portoricensis. A large series from Desecheo Island, which lies between Mona and Puerto Rico, would be interesting. Schmidt was hardly warranted in attributing A. antillensis to Puerto Rico on the strength of two specimens, one having seventeen rows. 
Schmidt (p. 141) states: "The identification of the two specimens collected by me at Coamo Springs as this species ( $A$. antillensis) removes the element of geographical distinctness from the allied $A$. portoricensis. The male specimen has only seventeen scale rows and so might be identified with $A$. portoricensis, were it not that the coloration of both specimens is nearly typical of $A$. antillensis." The species do seem to be geographically distinct. This opinion is based on eighty-four specimens, all in my collection. It will be noted that in the "table", characters considered specific by other writers have been omitted. A study of my series males this necessary, as no color or pattern is wholly specific. Without correct geographical data, it would be difficult to classify correctly all specimens.

As stated above, Culebra specimens have "clear white bellies" in alcohol. In life the chin and the anterior third or less of the belly is a bright straw yellow. This color was not seen in this species from other islands. 


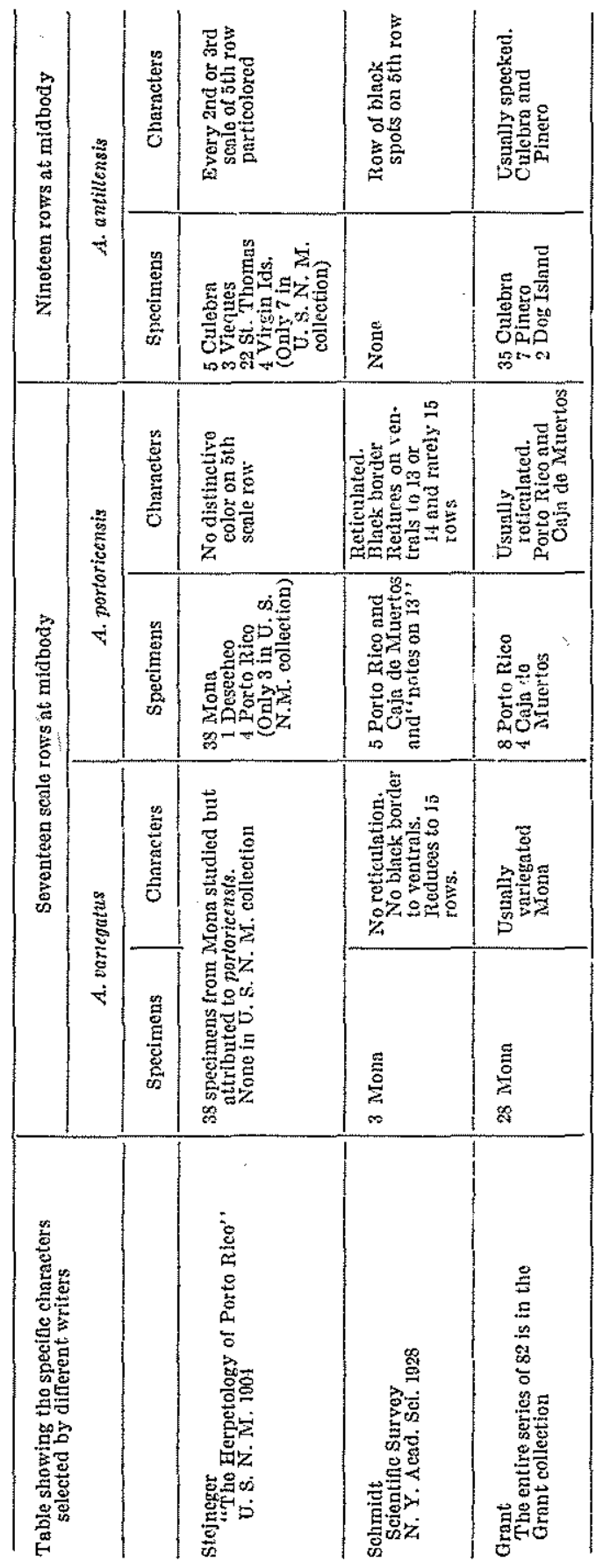

